\title{
Association between dietary inflammatory potential and breast cancer incidence and death: results from the Women's Health Initiative
}

Fred K Tabung ${ }^{1,2,3}$, Susan E Steck ${ }^{*}, 2,3,4$, Angela D Liese ${ }^{2,4}$, Jiajia Zhang ${ }^{2}$, Yunsheng Ma ${ }^{5}$, Bette Caan ${ }^{6}$, Rowan T Chlebowski ${ }^{7}$, Jo L Freudenheim ${ }^{8}$, Lifang Hou ${ }^{9}$, Yasmin Mossavar-Rahmani ${ }^{10}$, Nitin Shivappa ${ }^{2,3}$, Mara Z Vitolins ${ }^{11}$, Jean Wactawski-Wende ${ }^{8}$, Judith K Ockene ${ }^{5}$ and James R Hébert ${ }^{2,3}$

${ }^{1}$ Departments of Nutrition and Epidemiology, Harvard T. H. Chan School of Public Health, Boston, MA, USA; ${ }^{2}$ Department of Epidemiology and Biostatistics, Arnold School of Public Health, University of South Carolina, Columbia, SC, USA; ${ }^{3}$ Cancer Prevention and Control Program, University of South Carolina, Columbia, SC, USA; ${ }^{4}$ Center for Research in Nutrition and Health Disparities, University of South Carolina, Columbia, SC, USA; ${ }^{5}$ Division of Preventive and Behavioral Medicine, University of Massachusetts Medical School, Worcester, MA, USA; ${ }^{6}$ Kaiser Permanente Division of Research, Oakland, CA, USA; ${ }^{7}$ Los Angeles Biomedical Research Institute at Harbor-UCLA Medical Center (LABioMed), Torrance, CA, USA; ${ }^{8}$ Department of Epidemiology and Environmental Health, University at Buffalo, The State University of New York, Buffalo, NY, USA; ${ }^{9}$ Department of Preventive Medicine and the Robert H. Lurie Comprehensive Cancer Center, Feinberg School of Medicine, Northwestern University, Chicago, IL, USA; ${ }^{10}$ Department of Epidemiology and Population Health, Albert Einstein College of Medicine, Bronx, NY, USA and ${ }^{11}$ Department of Epidemiology \& Prevention, Wake Forest School of Medicine, Winston-Salem, NC, USA

Background: Diet modulates inflammation and inflammatory markers have been associated with cancer outcomes. In the Women's Health Initiative, we investigated associations between a dietary inflammatory index (DII) and invasive breast cancer incidence and death.

Methods: The DII was calculated from a baseline food frequency questionnaire in 122788 postmenopausal women, enrolled from 1993 to 1998 with no prior cancer, and followed until 29 August 2014. With median follow-up of 16.02 years, there were 7495 breast cancer cases and 667 breast cancer deaths. We used Cox regression to estimate multivariable-adjusted hazards ratios (HRs) and $95 \%$ confidence intervals $(95 \% \mathrm{Cls}$ ) by DII quintiles (Q) for incidence of overall breast cancer, breast cancer subtypes, and deaths from breast cancer. The lowest quintile (representing the most anti-inflammatory diet) was the reference.

Results: The DII was not associated with incidence of overall breast cancer $\left(\mathrm{HR}_{\mathrm{Q} 5 \mathrm{vs}} \mathrm{Q} 1,0.99 ; 95 \% \mathrm{Cl}, 0.91-1.07 ; P_{\text {trend }}=0.83\right.$ for overall breast cancer). In a full cohort analysis, a higher risk of death from breast cancer was associated with consumption of more pro-inflammatory diets at baseline, after controlling for multiple potential confounders (HR $\mathrm{Q}_{\mathrm{Q} v \mathrm{~s} Q 1}, 1.33$; 95\% Cl, 1.01-1.76; $\left.P_{\text {trend }}=0.03\right)$

Conclusions: Future studies are needed to examine the inflammatory potential of post-diagnosis diet given the suggestion from the current study that dietary inflammatory potential before diagnosis is related to breast cancer death.

*Correspondence: Dr SE Steck; E-mail: ssteck@sc.edu

A list of WHI investigators is included in the Supplementary Information as per the regulation governing the use of WHI data.

Received 7 December 2015; revised 2 March 2016; accepted 13 March 2016; published online 21 April 2016

(c) 2016 Cancer Research UK. All rights reserved 0007-0920/16 
Breast cancer is the most commonly diagnosed cancer and the second leading cause of cancer-related deaths among women in the United States (DeSantis et al, 2014; Siegel et al, 2015). Although there has been interest in the potential influence of dietary factors and dietary patterns on breast cancer incidence (Terry et al, 2001; Fung et al, 2005; Prentice et al, 2006) and survival (Chlebowski et al, 2006; Izano et al, 2013; George et al, 2014), the findings have been mixed. In addition, observational (Harris et al, 2003, 2011; Hong et al, 2013) and animal intervention studies (Howe et al, 2002; Brown et al, 2008) have found associations of inflammation with breast cancer risk, and dietary patterns have been shown to be linked to inflammation (Esposito et al, 2004; Ma et al, 2008; Barbaresko et al, 2013).

The recent development of a dietary inflammatory index (DII) (Shivappa et al, 2013a) provides a new tool to evaluate diets on a continuum from maximally anti-inflammatory to maximally proinflammatory. The DII was construct validated in a variety of studies, including the Women's Health Initiative (WHI), and found to predict concentrations of several inflammatory markers (Shivappa et al, 2013b, 2015a; Tabung et al, 2015b). Pro-inflammatory DII scores have also been consistently associated with higher risk of colorectal cancer in previous studies (Shivappa et al, 2014; Zamora-Ros et al, 2014; Steck et al, 2015; Wirth et al, 2015; Tabung et al, 2015a). However, two previous studies found conflicting results for the association of the DII with breast cancer incidence (Ge et al, 2015; Shivappa et al, 2015b). In the current study we utilised the DII to investigate the association of the inflammatory potential of diet with postmenopausal breast cancer incidence and death using data from the WHI.

\section{MATERIALS AND METHODS}

Participants. The WHI was designed to address the major causes of morbidity and mortality among postmenopausal women. The design of the WHI has been previously described (Women's Health Initiative Study Group, 1998). Briefly, WHI investigators enrolled 161808 postmenopausal women 50 to 79 years old with a predicted > 3-year survival in 40 sites in the United States between 1993 and 1998. Subjects were enrolled into one or more of three Clinical Trial (CT) groups $(n=68132)$ or the Observational Study $(n=93676)$. The CT had additional eligibility criteria and women were excluded from the Dietary Modification (DM) Trial if their diets were reported to have $<32 \%$ energy from fat as assessed by a food frequency questionnaire (FFQ) (Patterson et al, 1999). The WHI protocol was approved by the institutional review boards at the Clinical Coordinating Center (CCC) at the Fred Hutchinson Cancer Research Center (Seattle, WA, USA) and at each of the 40 Clinical Centers (Women's Health Initiative Study Group, 1998).

Diet assessment. During screening for the WHI, all participants completed a standardised self-administered 122-item FFQ developed for the WHI to estimate average daily nutrient intake over the previous 3-month period. These data served as the baseline dietary measures. The FFQ data were considered complete if all adjustment questions, all summary questions, $90 \%$ of the foods, and at least one-half of every food group section was completed (Patterson et al, 2003; Women's Health Initiative Study Group, 1998). The nutrient database, linked to the University of Minnesota Nutrition Data System for Research (NDSR) (Nutrition Coordinating Center at the University of Minnesota, 2013), is based on the US Department of Agriculture Standard Reference Releases and manufacturer information. The WHI FFQ has produced results comparable to those from four 24-h dietary recall interviews and 4 days of food diaries recorded within the WHI study population (Patterson et al, 1999).
Description of the DII. Details of the development (Shivappa et al, 2013a) and construct validation (Shivappa et al, 2013b; Tabung et al, 2015b) of the DII have been described elsewhere. Briefly, an extensive literature search was performed to identify articles published in peer-reviewed journals reporting on studies that examined the association between dietary factors and six inflammatory markers (interleukin (IL)-1 $\beta$, IL-4, IL-6, IL-10, tumour necrosis factor- $\alpha(\mathrm{TNF} \alpha)$, and C-reactive protein (CRP)). A total of 1943 eligible articles published through 2010 were indexed and scored to derive component-specific inflammatory effect scores. In the process of reading and scoring these articles, a total of 45 specific foods and nutrients (components of the DII) were identified.

Actual dietary intake data derived from baseline WHI FFQ were standardised to a representative global diet database constructed based on 11 data sets from diverse populations in different parts of the world. The standardised dietary intake data were then multiplied by the literature-derived inflammatory effect scores for each DII component, and summed across all components, to obtain the overall DII (Shivappa et al, 2013a). A higher DII score indicates a more inflammatory diet and a lower (i.e., more negative) DII score indicates a less inflammatory diet. In the WHI FFQ, 32 of the 45 original DII components were available for inclusion in the overall DII (see Tabung et al, 2015b and Table 1 for the list of the 32 DII components included in the WHI DII calculation). The components ginger, turmeric, garlic, oregano, pepper, rosemary, eugenol, saffron, flavan-3-ol, flavones, flavonols, flavonones, and anthocyanidins that are included in the original DII calculation (Shivappa et al, 2013a) were not included in the current study because they were not available from the WHI FFQ. The DII has been construct validated in the WHI and found to significantly predict concentrations of IL- 6 and TNF $\alpha$ receptor 2 expression (Tabung et al, 2015b).

Outcome ascertainment. Outcomes included breast cancer event (diagnosis of invasive breast cancer or confirmation of breast cancer-related death) and time to breast cancer event. As previously described (Curb et al, 2003), breast cancers were initially verified by medical record and pathology report review by physician adjudicators at each clinical centre, with final adjudication centrally by WHI cancer coders (Curb et al, 2003).

Breast cancer subtypes for analysis were defined based on oestrogen receptor (ER), progesterone receptor (PR), and human epidermal growth factor receptor 2 (HER2) status (Calhoun and Collins, 2015), and combined as triple-negative (ER -, PR - , HER2 - ); luminal A (ER + and/or PR + , HER2 - ); luminal B $(\mathrm{ER}+$ and/or $\mathrm{PR}+, \mathrm{HER} 2+)$; and $\mathrm{ER}-, \mathrm{PR}-, \mathrm{HER} 2+$ subtypes (Parise and Caggiano, 2014). The histological subtypes were defined based on Surveillance Epidemiology and End Results program morphology codes. These included invasive ductal carcinoma (8500/3) and invasive lobular carcinoma (8520/2). The in situ breast cancer cases were not included.

Time-to-breast-cancer-event (diagnosis or death) was defined as days from enrolment or randomisation until invasive breast cancer diagnosis or confirmation of breast cancer death. Censoring time for breast cancer incidence models was defined as days from enrolment or randomisation until death or last contact occurring on or before 29 August 2014 in participants without breast cancer; for breast cancer death (fatal breast cancer) models, censoring time was the number of days from enrolment/randomisation until last contact occurring on or before 29 August 2014 in participants who were still alive.

Statistical analyses. Data on 149790 women from both the OS and the CT were considered for the current analyses. Through 29 August 2014, 7495 women were diagnosed with invasive breast cancer and 667 breast cancer deaths were confirmed. The following exclusion criteria were applied to both sets of analyses: any cancer 
Table 1. Participant baseline characteristics $(n, \%)$ by quintiles (Q) of the dietary inflammatory index (DII) ${ }^{\text {; }}$; Women's Health Initiative ( $n=122788) ; 1993-1998$

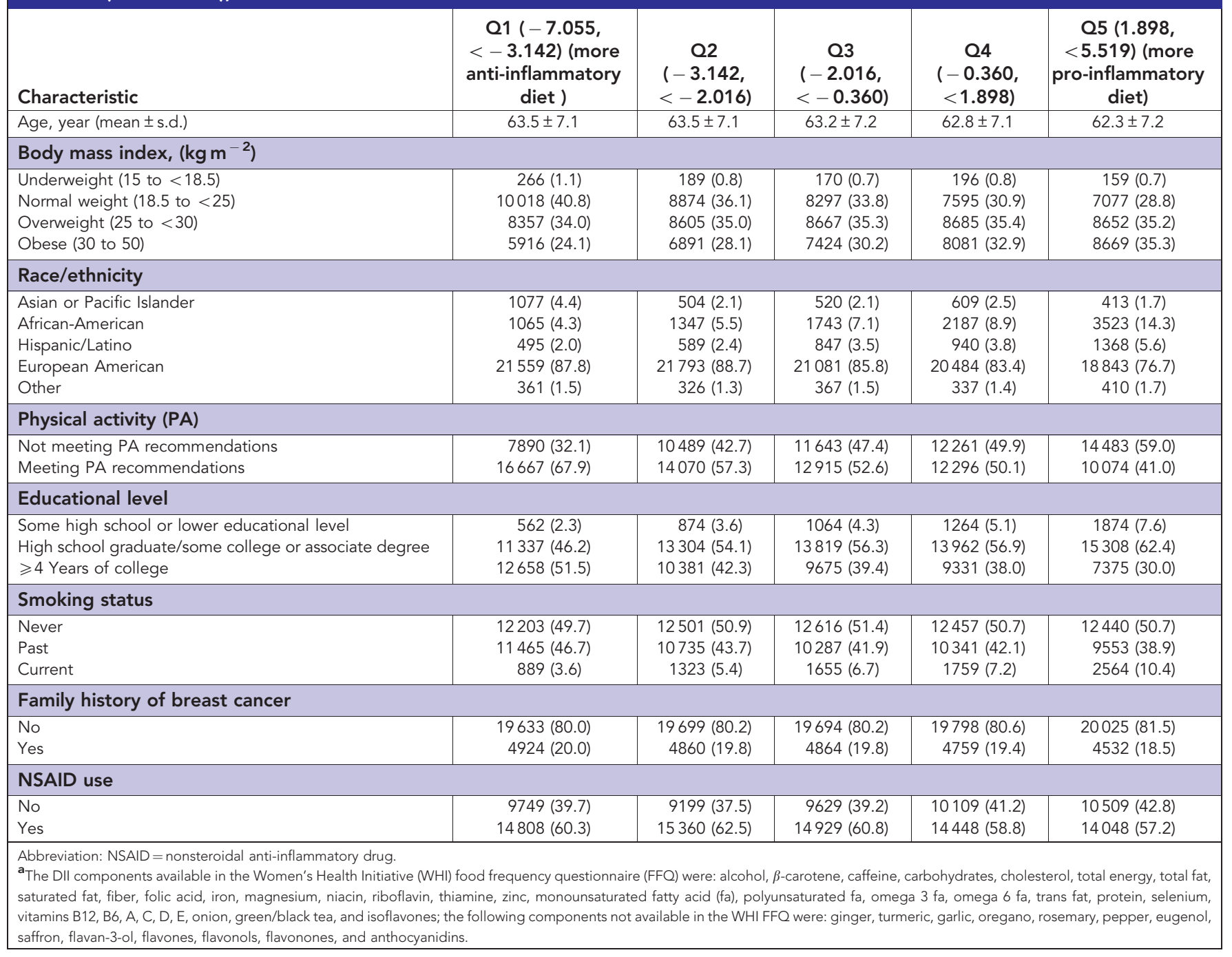

(except non-melanoma skin cancer) before study entry or missing prior cancer status $(n=10858)$, mastectomy at baseline $(n=268)$, any cancer (except non-melanoma skin cancer) diagnosed within 2 years from baseline during follow-up $(n=2032)$, implausible reported total energy intake values ( $\leqslant 600$ or $\geqslant 5000 \mathrm{kcal}$ per day; $n=4219)$ or extreme body mass index (BMI) values $(<15$ or $\left.>50 \mathrm{~kg} \mathrm{~m}^{-2} ; n=733\right)$. Participants with missing data in the covariates listed below $(n=8892)$ were excluded, leaving a total of 122788 participants for the current analyses. Frequencies and percentages were used to describe the distribution of covariates across quintiles of the DII.

We used Cox regression models to calculate hazard ratios (HRs), associated 95\% confidence intervals (95\% CIs), and linear trends for invasive breast cancer, breast cancer subtypes, breast cancer stages, and breast cancer-related death, for DII quintiles with adjustment for multiple covariates. The lowest DII quintile (representing the most anti-inflammatory diet) was the referent for all models. The analysis of breast cancer death was a full cohort analysis of fatal breast cancer outcomes. Potential effect modification of the association between the DII and breast cancer incidence and death by age, BMI, regular nonsteroidal anti-inflammatory drug (NSAID) use, and hormone use was investigated by including DII $\times$ covariate interaction terms in the Cox regression models; none of the interaction terms was significant at $P<0.10$. Tests of linear trend across DII quintiles were computed by assigning the median value of each quintile to each participant in the quintile and this ordinal variable was entered into models and its $P$-value evaluated for significant trend.

Data on potential confounders were collected by standardised self-administered questionnaires on demographics, medical history, and lifestyle factors. In bivariate analyses including the DII and each of these potential confounders, a change of $\geqslant 10 \%$ in the HR comparing the univariate model with DII only with the bivariate model resulted in inclusion of the covariate in the fully adjusted model. Multivariable Cox regression models were adjusted for the following covariates: age (continuous, years), race/ethnicity (European American, African American, Hispanic, Asian or Pacific Islander, and Other), BMI (underweight (15 to $<18.5 \mathrm{~kg} \mathrm{~m}^{-2}$ ), normal weight ( 18.5 to $<25 \mathrm{~kg} \mathrm{~m}^{-2}$ ), overweight (25 to $<30 \mathrm{~kg} \mathrm{~m}^{-2}$ ), and obese (30 to $50 \mathrm{~kg} \mathrm{~m}^{-2}$ )); physical activity (PA) categorised based on current public health recommendations (Department of Health and Human Services, 2008), as meeting or not meeting PA recommendations $(\geqslant 150 \mathrm{~min}$ per week of moderate intensity PA or $\geqslant 60$ min per week of vigorous intensity PA $v s<150$ min per week of moderate intensity PA or $<60$ min per week of vigorous intensity PA, respectively), education (some high school or lower educational level, high school graduate/some college or associate degree, $\geqslant 4$ years of college), family income $(<\$ 10000, \$ 10000-\$ 19999$, \$20000$\$ 34$ 999, \$35000-\$49999, \$50 000-\$74 999, \$75000-\$99999, 
$\$ 100000-\$ 149999, \geqslant \$ 150000$ ), smoking status (current, past, and never), family history of breast cancer (yes/no), mammography use within 2 years of baseline (yes/no), age at menarche $(<10,11-15, \geqslant 16$ years), number of live births (none, $1-3, \geqslant 4)$, oophorectomy status (no ovaries removed, one or both ovaries removed), hormone therapy use (never, former, current), regular (at least twice a week for the previous 2 weeks; Coghill et al, 2012) use of NSAID (yes/no), DM arm (intervention, control, not randomised to DM), HRT arm (oestrogen-alone intervention, oestrogen-alone control, oestrogen and progesterone intervention, oestrogen and progesterone control, not randomised to HRT), calcium and vitamin $\mathrm{D}(\mathrm{CaD})$ trial arm (intervention, control, not randomised to $\mathrm{CaD}$ ), and total energy intake (Kcal per day). The proportional hazards assumption was assessed for each covariate using Martingale-based residuals. The $\mathrm{CaD}$ arm violated the assumption in both the incidence and death analyses, and all Cox regression models were thus stratified by $\mathrm{CaD}$.

We conducted several sensitivity analyses; first, we excluded women diagnosed with $(n=1517)$, or who died from $(n=11)$, breast cancer within 3 years from baseline to reduce the likelihood that results reflected the presence of subclinical disease at baseline (McBride et al, 2000; Patterson et al, 2012). Second, we conducted incidence and death analyses excluding women diagnosed with any cancer at any time point before the diagnosis of breast cancer. Third, we stratified by WHI study arm (OS and CT) to ensure that results were not sensitive to the WHI study design. Finally, we compared women with and without missing data in the covariates included in the multivariable models to ensure that the women excluded because of missing data were not systematically different from the women retained for final analysis.

\section{RESULTS}

After applying all exclusion criteria, a total of 7495 cases of incident invasive breast cancer (average 15.1 years (1 848542.1 person-years) of follow-up) and 667 breast cancer deaths (average 16.6 years (1 672710.1 person-years) of follow-up) were available for analyses. The mean ( \pm s.d.) DII score was $-0.78( \pm 2.61)$, and ranged from a maximally anti-inflammatory score of -7.06 to a maximally pro-inflammatory score of +5.79 . Table 1 presents the distribution of participants' characteristics across quintiles of the DII. Participants consuming the most inflammatory diets (classified in the highest quintile) were more likely to be obese, African
American or Hispanic, not meeting public health recommendations for physical activity, and reported a low level of education, compared with their counterparts who consumed more antiinflammatory diets (i.e., likely to fall into lower DII quintiles, Table 1).

There was no statistically significant association between the DII and risk of overall breast cancer incidence. In the multivariableadjusted model, the HR (and 95\% CI) comparing women in the highest with those in the lowest DII quintile was 0.99 (95\% CI, 0.91-1.07; Table 2). There was a positive association between the DII and overall breast cancer death in the fourth and fifth quintiles compared with the lowest quintile of DII in the age and energy intake-adjusted model $\left(\mathrm{HR}_{\mathrm{Q} 4 v s \mathrm{Q} 1}, 1.51 ; 95 \% \mathrm{CI}, 1.18-1.94\right.$ and $\left.\mathrm{HR}_{\mathrm{Q} 5 v_{\mathrm{Q}} 1}, 1.53 ; 95 \% \mathrm{CI}, 1.18-2.00 ; P_{\text {trend }}, 0.0005\right)$. The association between the DII and breast cancer death was slightly attenuated, but persisted even after controlling for BMI, physical activity, education, smoking status, hormone therapy use, regular NSAID use, $\mathrm{DM}$ arm, and screening history $\left(\mathrm{HR}_{\mathrm{Q} 4 v s \mathrm{Q} 1}, 1.38 ; 95 \% \mathrm{CI}\right.$, $1.07-1.79$ and $\mathrm{HR}_{\mathrm{Q} 5 v \mathrm{Q} 1}, 1.33 ; 95 \% \mathrm{CI}, 1.01-1.76 ; P_{\text {trend }}=0.03$; Table 2). Both BMI and physical activity were largely responsible for the attenuation of HRs in the multivariable-adjusted model. The HRs in the fourth and fifth DII quintiles without adjusting for BMI and physical activity were: $\mathrm{HR}_{\mathrm{Q} 4 v s \mathrm{Q} 1}, 1.48$; 95\% CI, 1.15-1.90 and $\mathrm{HR}_{\mathrm{Q} 5 v s \mathrm{Q} 1}, 1.46 ; 95 \% \mathrm{CI}, 1.11-1.93 ; P_{\text {trend }}=0.002$.

Table 3 presents HRs for the association between DII quintiles and subtypes and stage of breast cancer. There was a tendency towards higher risk of breast cancer subtypes that included HER2 + (i.e., luminal B (ER + and/or PR +, HER2 + ) and $(\mathrm{ER}-, \mathrm{PR}-, \mathrm{HER} 2+)$ subtypes) with higher DII scores that did not attain statistical significance. Irrespective of ER or PR status, risk of HER $2+$ breast cancer subtype was significantly higher in women in quintile 4 compared with those in quintile 1 (HR, 1.33; 95\% CI, 1.05-1.67); however, risk appeared to be attenuated (and nonsignificant) in quintile 5 ( $\mathrm{HR}, 1.11 ; 95 \% \mathrm{CI}, 0.85-1.44$; $\left.P_{\text {trend }}=0.24\right)$. There was no association between the DII and localised breast cancer. However, there was a suggestion of an inverse association between the DII and regional/distant disease $\left(\mathrm{HR}_{\mathrm{Q} 5 v s \mathrm{Q} 1}, 0.84 ; 95 \% \mathrm{CI}, 0.79-1.00 ; P_{\text {trend }}=0.03\right)$.

In sensitivity analyses (Table 4 ), results for overall breast cancer incidence and breast cancer death did not materially change when we excluded breast cancer cases and deaths that occurred within 3 years from baseline. The findings also did not change materially when all other cancers diagnosed before breast cancer were excluded (Supplementary Table 1). Results in the OS were not

Table 2. Hazard ratios of the association between the dietary inflammatory index (DII) and breast cancer incidence and death; Women's Health Initiative $(n=122788), 1993-2014$

\begin{tabular}{|c|c|c|c|c|c|c|}
\hline Breast cancer incidence & $\begin{array}{c}\text { Q1 }(-7.055 \\
<-3.142) \text { (more } \\
\text { anti-inflammatory } \\
\text { diet) }\end{array}$ & $\begin{array}{c}\mathrm{Q} 2 \\
(-3.142 \\
<-2.016)\end{array}$ & $\begin{array}{c}\text { Q3 } \\
(-2.016 \\
<-0.360)\end{array}$ & $\begin{array}{c}\text { Q4 } \\
(-0.360 \\
<1.898)\end{array}$ & $\begin{array}{c}\text { Q5 (1.898, } \\
5.519) \text { (more } \\
\text { pro-inflammatory } \\
\text { diet) }\end{array}$ & $P_{\text {trend }}{ }^{a}$ \\
\hline HR $(95 \% \mathrm{Cl})$, age- and energy-adjusted model & 1.00 & $0.98(0.91,1.05)$ & $0.91(0.85,0.98)$ & $0.97(C$ & $0)$ & 0.09 \\
\hline HR (95\% Cl), multivariable-adjusted model ${ }^{c}$ & 1.00 & $0.98(0.91,1.05)$ & $0.93(0.86,1.00)$ & $1.00(0.93,1.07)$ & $0.99(0.91,1.07)$ & 0.83 \\
\hline Breast cancer death & $\begin{array}{c}\text { Q1 }(-7.055, \\
<-3.162)\end{array}$ & $\begin{array}{c}\mathrm{Q} 2(-3.162, \\
<-2.032)\end{array}$ & $\begin{array}{c}\text { Q3 }(-2.032, \\
<-0.374)\end{array}$ & $\begin{array}{c}\text { Q4 }(-0.374 \\
<1.874)\end{array}$ & $\begin{array}{c}\text { Q5 (1.874, } \\
5.519)\end{array}$ & \\
\hline Breast cancer death, $n=667, n(\%)^{b}$ & $108(0.53 \%)$ & $127(0.63 \%)$ & $138(0.68 \%)$ & $152(0.75 \%)$ & $142(0.70 \%)$ & \\
\hline HR $(95 \% \mathrm{Cl})$, age- and energy-adjusted model & 1.00 & $1.21(0.94,1.57)$ & $1.35(1.05,1.74)$ & $1.51(1.18,1.94)$ & $1.53(1.18,2.00)$ & 0.0005 \\
\hline HR $(95 \% \mathrm{Cl})$, multivariable-adjusted model ${ }^{\mathrm{c}}$ & 1.00 & $1.15(0.89,1.49)$ & $1.25(0.97,1.62)$ & $1.38(1.07,1.79)$ & $1.33(1.01,1.76)$ & 0.03 \\
\hline \multicolumn{7}{|c|}{ 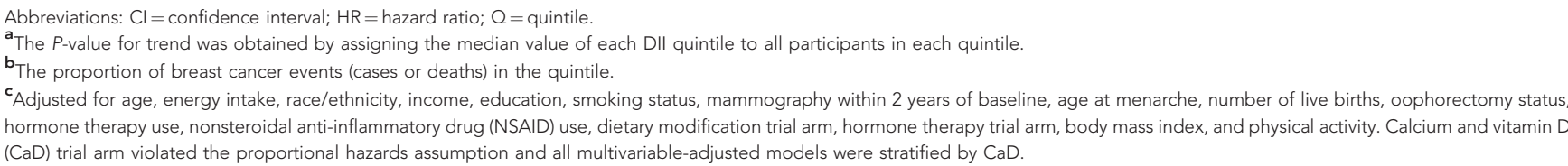 } \\
\hline
\end{tabular}


Table 3. Risk of breast cancer by subtype and stage at diagnosis, across quintiles of the dietary inflammatory index (DII); Women's Health Initiative $(n=122788), 1993-2014$

\begin{tabular}{|c|c|c|c|c|c|c|}
\hline & $\begin{array}{c}\text { Referent } \\
\text { Q1 } \\
(-7.055,<-3.145) \\
\text { (more anti- } \\
\text { inflammatory diet ) }\end{array}$ & $\begin{array}{c}\text { Q2 }(-3.145 \\
<-2.026)\end{array}$ & $\begin{array}{c}\text { Q3 }(-2.026 \\
<-0.377)\end{array}$ & $\begin{array}{c}\text { Q4 }(-0.377 \\
<1.884)\end{array}$ & $\begin{array}{c}\text { Q5 (1.884, } \\
<5.789) \\
\text { (more pro- } \\
\text { inflammatory } \\
\text { diet) }\end{array}$ & $P_{\text {trend }}{ }^{\mathrm{a}}$ \\
\hline \multicolumn{7}{|l|}{ Molecular subtypes } \\
\hline $\begin{array}{l}E R+; n=5943 \text { cases, } n(\%)^{b} \\
H R(95 \% \mathrm{Cl})\end{array}$ & $\begin{array}{c}1288(5.30 \%) \\
1.00\end{array}$ & $\begin{array}{l}1225(5.05 \%) \\
0.97(0.90,1.05)\end{array}$ & $\begin{array}{l}1138(4.69 \%) \\
0.93(0.85,1.00)\end{array}$ & $\begin{array}{l}1210(4.99 \%) \\
1.00(0.92,1.08)\end{array}$ & $\begin{array}{c}1082(4.46 \%) \\
0.97(0.89,1.06)\end{array}$ & 0.88 \\
\hline $\begin{array}{l}\text { ER }-; n=1025 \text { cases, } n(\%) \\
\text { HR }(95 \% \mathrm{Cl})\end{array}$ & $\begin{array}{c}198(0.86 \%) \\
1.00\end{array}$ & $\begin{array}{l}212(0.91 \%) \\
1.09(0.90,1.33)\end{array}$ & $\begin{array}{c}190(0.81 \%) \\
0.98(0.80,1.21)\end{array}$ & $\begin{array}{l}214(0.92 \%) \\
1.11(0.91,1.36)\end{array}$ & $\begin{array}{l}211(0.90 \%) \\
1.13(0.91,1.41)\end{array}$ & 0.27 \\
\hline $\begin{array}{l}\mathrm{PR}+; n=5001 \text { cases, } n(\%) \\
\mathrm{HR}(95 \% \mathrm{Cl})\end{array}$ & $\begin{array}{c}1067(4.44 \%) \\
1.00\end{array}$ & $\begin{array}{l}1028(4.27 \%) \\
0.99(0.90,1.08)\end{array}$ & $\begin{array}{c}966(4.01 \%) \\
0.95(0.87,1.04)\end{array}$ & $\begin{array}{l}1041(4.32 \%) \\
1.03(0.95,1.13)\end{array}$ & $\begin{array}{l}899(3.74 \%) \\
0.98(0.89,1.08)\end{array}$ & 0.84 \\
\hline $\begin{array}{l}\text { PR }-; n=1859 \text { cases, } n(\%) \\
\text { HR }(95 \% \mathrm{Cl})\end{array}$ & $\begin{array}{c}398(1.70 \%) \\
1.00\end{array}$ & $\begin{array}{l}377(1.61 \%) \\
0.97(0.84,1.12)\end{array}$ & $\begin{array}{l}344(1.47 \%) \\
0.90(0.78,1.05)\end{array}$ & $\begin{array}{l}372(1.59 \%) \\
0.98(0.85,1.14)\end{array}$ & $\begin{array}{l}368(1.56 \%) \\
1.03(0.87,1.20)\end{array}$ & 0.60 \\
\hline $\begin{array}{l}\text { HER2 }+; n=771 \text { cases, } n(\%) \\
\text { HR }(95 \% \mathrm{Cl})\end{array}$ & $\begin{array}{l}139(0.60 \%) \\
1.00\end{array}$ & $\begin{array}{l}151(0.65 \%) \\
1.11(0.88,1.40)\end{array}$ & $\begin{array}{c}163(0.70 \%) \\
1.21(0.96,1.52)\end{array}$ & $\begin{array}{l}178(0.77 \%) \\
1.33(1.05,1.67)\end{array}$ & $\begin{array}{l}140(0.60 \%) \\
1.11(0.85,1.44)\end{array}$ & 0.24 \\
\hline $\begin{array}{l}\text { HER2 }-; n=4731 \text { cases, } n(\%) \\
\text { HR }(95 \% \mathrm{Cl})\end{array}$ & $\begin{array}{l}1039(4.33 \%) \\
1.00\end{array}$ & $\begin{array}{l}953(3.98 \%) \\
0.94(0.86,1.02)\end{array}$ & $\begin{array}{l}895(3.73 \%) \\
0.90(0.82,0.98)\end{array}$ & $\begin{array}{l}956(3.98 \%) \\
0.96(0.88,1.05)\end{array}$ & $\begin{array}{l}888(3.69 \%) \\
0.96(0.87,1.07)\end{array}$ & 0.91 \\
\hline $\begin{array}{l}\text { ER }-, P R-, H E R 2+; n=205 \text { cases, } n(\%) \\
\text { HR }(95 \% \mathrm{Cl})\end{array}$ & $\begin{array}{l}35(0.15 \%) \\
1.00\end{array}$ & $\begin{array}{c}34(0.15 \%) \\
1.02(0.63,1.65)\end{array}$ & $\begin{array}{c}47(0.20 \%) \\
1.41(0.90,2.21)\end{array}$ & $\begin{array}{c}45(0.19 \%) \\
1.36(0.86,2.15)\end{array}$ & $\begin{array}{c}44(0.19 \%) \\
1.42(0.86,2.34)\end{array}$ & 0.11 \\
\hline $\begin{array}{l}\text { Luminal A (ER }+ \text { and/or PR }+, \text { HER2 - ); } n=4202 \text { cases, } n(\%) \\
\text { HR }(95 \% \mathrm{Cl})\end{array}$ & $\begin{array}{l}935(3.91 \%) \\
1.00\end{array}$ & $\begin{array}{l}840(3.52 \%) \\
0.92(0.83,1.01)\end{array}$ & \begin{tabular}{l|l}
$802(3.35 \%)$ \\
$0.89(0.81,0.98)$
\end{tabular} & $\begin{array}{l}848(3.55 \%) \\
0.95(0.86,1.05)\end{array}$ & $\begin{array}{l}777(3.25 \%) \\
0.94(0.85,1.05)\end{array}$ & 0.67 \\
\hline $\begin{array}{l}\text { Luminal B (ER }+ \text { and/or PR }+, \text { HER2 }+) ; n=554 \text { cases, } n(\%) \\
\text { HR }(95 \% \mathrm{Cl})\end{array}$ & $\begin{array}{l}104(0.45 \%) \\
1.00\end{array}$ & $\begin{array}{l}115(0.50 \%) \\
1.11(0.84,1.45)\end{array}$ & $\begin{array}{l}113(0.49 \%) \\
1.10(0.83,1.44)\end{array}$ & $\begin{array}{l}128(0.55 \%) \\
1.25(0.96,1.63)\end{array}$ & $\begin{array}{c}94(0.40 \%) \\
0.96(0.70,1.30)\end{array}$ & 0.96 \\
\hline $\begin{array}{l}\text { Triple negative (ER - , PR - , HER2 - ); } n=509 \text { cases, } n(\%) \\
\text { HR }(95 \% \mathrm{Cl})\end{array}$ & $\begin{array}{l}99(0.43 \%) \\
1.00\end{array}$ & $\begin{array}{l}109(0.47 \%) \\
1.12(0.85,1.48)\end{array}$ & $\begin{array}{c}90(0.39 \%) \\
0.93(0.69,1.24)\end{array}$ & $\begin{array}{l}104(0.45 \%) \\
1.06(0.80,1.42)\end{array}$ & $\begin{array}{l}107(0.46 \%) \\
1.11(0.82,1.51)\end{array}$ & 0.60 \\
\hline \multicolumn{7}{|l|}{ Histologic subtypes } \\
\hline $\begin{array}{l}\text { Invasive ductal carcinoma; } n=4767 \text { cases, } n(\%) \\
\text { HR }(95 \% \mathrm{Cl})\end{array}$ & $\begin{array}{l}1007(4.20 \%) \\
1.00\end{array}$ & $\begin{array}{l}998(4.16 \%) \\
1.00(0.92,1.09)\end{array}$ & \begin{tabular}{l|l|}
$917(3.81 \%)$ \\
$0.93(0.85,1.02)$
\end{tabular} & $\begin{array}{c}962(4.01 \%) \\
0.98(0.89,1.07)\end{array}$ & $\begin{array}{c}883(3.67 \%) \\
0.94(0.85,1.04)\end{array}$ & 0.26 \\
\hline $\begin{array}{l}\text { Invasive lobular carcinoma; } n=758 \text { cases, } n(\%) \\
\text { HR }(95 \% \mathrm{Cl})\end{array}$ & $\begin{array}{l}172(0.74 \%) \\
1.00\end{array}$ & $\begin{array}{l}151(0.65 \%) \\
0.91(0.73,1.14)\end{array}$ & $\begin{array}{l}139(0.60 \%) \\
0.87(0.69,1.09)\end{array}$ & $\begin{array}{l}153(0.66 \%) \\
0.98(0.78,1.23)\end{array}$ & $\begin{array}{l}143(0.61 \%) \\
1.01(0.79,1.30)\end{array}$ & 0.65 \\
\hline \multicolumn{7}{|l|}{ Stage at diagnosis } \\
\hline Localised; $n=5567$ cases & $\begin{array}{c}1217(5.03 \%) \\
1.00\end{array}$ & $\begin{array}{l}1054(4.77 \%) \\
0.94(0.86,1.02)\end{array}$ & \begin{tabular}{r|}
$1036(4.29 \%)$ \\
$0.99(0.91,1.08)$
\end{tabular} & $\begin{array}{l}1141(4.72 \%) \\
0.99(0.91,1.08)\end{array}$ & $\begin{array}{l}1019(4.22 \%) \\
1.00(0.88,1.06)\end{array}$ & 0.97 \\
\hline Regional/distant; $n=1799$ cases & $\begin{array}{l}363(1.56 \%) \\
1.00 \\
\end{array}$ & $\begin{array}{l}361(1.54 \%) \\
1.01(0.87,1.17)\end{array}$ & $\begin{array}{l}369(1.57 \%) \\
0.98(0.85,1.15) \\
\end{array}$ & $\begin{array}{l}351(1.50 \%) \\
0.97(0.83,1.13)\end{array}$ & $\begin{array}{l}355(1.51 \%) \\
0.84(0.79,1.00)\end{array}$ & 0.03 \\
\hline \multicolumn{7}{|c|}{$\begin{array}{l}\text { Abbreviations: } \mathrm{Cl}=\text { confidence interval; } \mathrm{ER}=\text { oestrogen receptor; } \mathrm{HER} 2=\text { human epidermal growth factor receptor } 2 ; \mathrm{HR}=\text { hazard ratio; } \mathrm{PR}=\text { progesterone receptor; } \mathrm{Q}=\mathrm{quintile} \text {. All models } \\
\text { were adjusted for age, race/ethnicity, income, education, body mass index, physical activity, smoking status, mammography within } 2 \text { years of baseline, age at menarche, number of live births, } \\
\text { oophorectomy status, hormone therapy use, nonsteroidal anti-inflammatory drug (NSAID) use, dietary modification trial arm, hormone therapy trial arm, and energy intake. Calcium and vitamin } \\
\mathrm{D}(\mathrm{CaD}) \text { trial arm violated the proportional hazards assumption and all multivariable-adjusted models were stratified by CaD. Case frequencies were obtained after excluding participants with } \\
\text { missing data in the covariates. } \\
\mathrm{a}^{\mathrm{a}} \text { The } P \text {-value for trend was obtained by assigning the median value of each DIl quintile to all participants in the quintile. } \\
\text { b }_{\text {The proportion of breast cancer events (cases or deaths) in each quintile. }}\end{array}$} \\
\hline
\end{tabular}

materially different than in the CT when stratified by WHI study participation (data not shown). Comparing demographic and other characteristics of women who were excluded because of missing data $v s$ those included in the analyses did not reveal substantial differences between these two populations (data not shown).

\section{DISCUSSION}

In this large prospective investigation of pre-diagnosis dietary inflammatory potential in postmenopausal women, a more pro-inflammatory diet was not associated with higher risk of overall breast cancer incidence. However, there was a significantly higher risk of breast cancer death with higher baseline DII scores in a full cohort analysis. In subgroup analyses, higher DII was also associated with a higher risk of HER2 + breast cancer in the fourth quintile of DII score, but not in the fifth (highest) quintile.

Similar to our finding, most prospective observational studies (Smith-Warner et al, 2001; Terry et al, 2001; Adebamowo et al,
2005; Fung et al, 2005) and clinical trials (Prentice et al, 2006) have not found a significant association between higher diet quality as assessed by other dietary patterns and overall breast cancer risk. Diet quality is inversely related to the inflammatory potential of diet, that is, higher quality diets would have lower DII scores (Wirth et al, 2016). In the WHI-DM Trial, where a low-fat dietary pattern was assessed, after 9.1 years of follow up, there appeared to be fewer invasive breast cancers in the dietary intervention group. However, the difference was not statistically significant (HR, 0.91; 95\% CI, 0.83-1.01) (Prentice et al, 2006). A prospective study examining the association of several diet quality scores, including the Healthy Eating Index, Alternate Healthy Eating Index, Diet Quality Index-Revised, and Recommended Food Score (the sum of 23 recommended food items consumed at least weekly), did not find a significant association with overall breast cancer risk, though risk of ER-negative tumours was lower with higher Recommended Food Scores (Fung et al, 2006).

Two studies have found conflicting results of the association between the DII and breast cancer incidence. A case-control study from Germany found no association (Ge et al, 2015), whereas a prospective cohort study in Sweden reported a positive association 
Table 4. Hazard ratios of the association between the dietary inflammatory index (DII) and breast cancer incidence and death, with the exclusion of breast cancer cases and deaths that occurred within 3 years from baseline; Women's Health Initiative $(n=122788), 1993-2014$

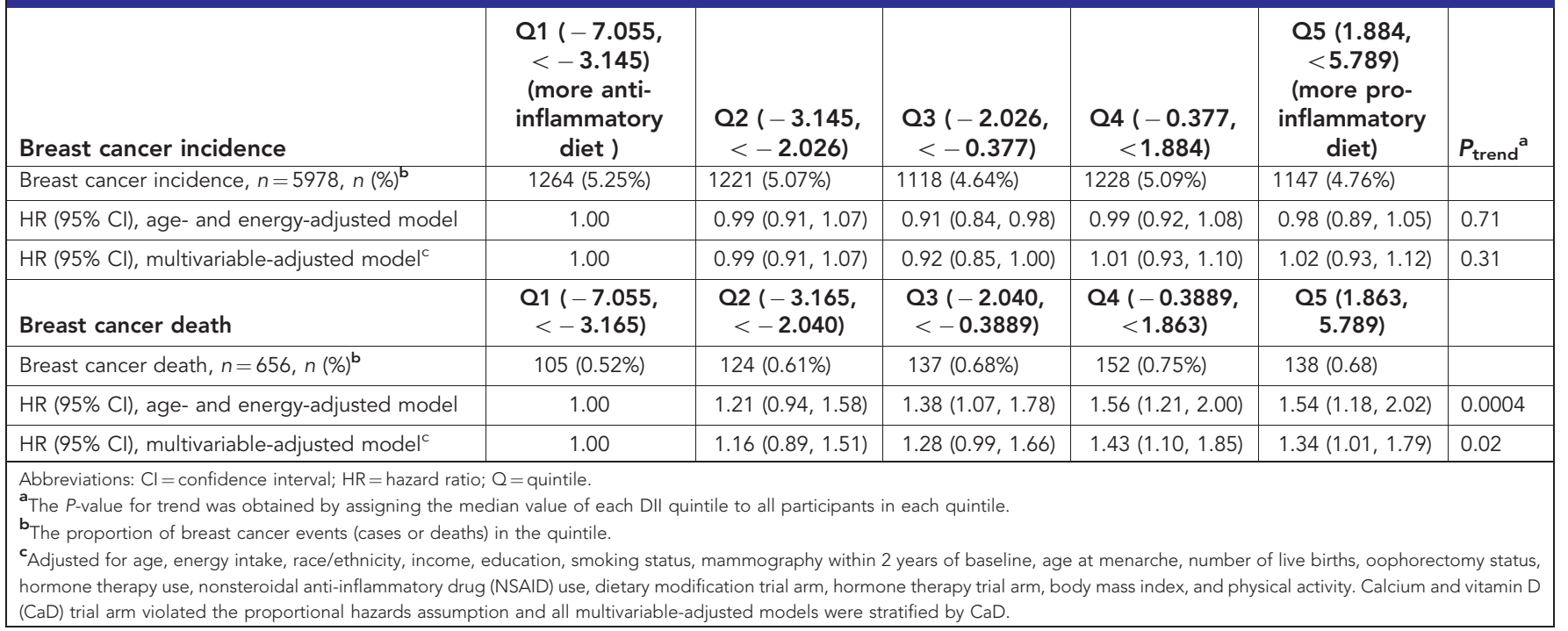

(Shivappa et al, 2015b) between higher DII scores and risk of breast cancer. Our study of postmenopausal American women may differ from these two previous studies because of differences in dietary inflammatory potential of the study populations. The mean ( \pm s.d.) DII scores in the Swedish $(2.67 \pm 1.47)$ and German $(0.85 \pm 1.30)$ studies were more pro-inflammatory compared with the current study $(-0.78 \pm 2.61)$.

It is possible that diet may differentially influence breast cancer development based on the cancer phenotype. Similar to our differential findings by HER2 subtypes, another prospective study, in Italy, found an association between higher consumption of salad vegetables and lower risk of HER2 + breast cancer, and a suggestion of higher risk of HER2 - breast cancer with more prudent dietary patterns (Sant et al, 2007). The WHI low-fat intervention trial investigated breast cancer risk by tumour characteristics including hormone receptor status. The HR estimate was not related to ER status, but was lower for PRnegative tumours than for PR-positive tumours $(P=0.04)$. When tumours were classified by both ER and PR status, there was an indication $(P=0.04)$ of $\mathrm{HR}$ variation with stronger evidence for a reduction in the occurrence of tumours that were ER positive and PR negative. The HER2 status was not available for breast cancers diagnosed early in that trial and was therefore not investigated (Prentice et al, 2006). Overall, findings from this previous study of the WHI-DM provide further support for a potential differential role of diet on breast cancer risk by cancer phenotype. Given the lack of dose response, and smaller number of HER2 + cases in the current study, future studies examining association between diet quality and breast cancer phenotypes are warranted. Similarly, the suggestion of an inverse trend between the DII and risk of regional/ distant breast cancer was unexpected as there is no precedent for a similar result in the literature.

Our result of higher risk of breast cancer death with higher consumption of pro-inflammatory diets is similar to the finding by Mai et al (2005), who observed a moderate association between pre-diagnosis diet and risk of breast cancer death. They found a $25 \%$ lower risk of breast cancer-related death ( $\mathrm{HR}, 0.75 ; 95 \% \mathrm{CI}$, $\left.0.56-1.00 ; P_{\text {trend }}=0.06\right)$ for women in the highest quartile compared with the lowest quartile of Recommended Food Score after adjusting for potential confounding factors (Mai et al, 2005). The potential role of chronic inflammation in breast cancer death is supported by evidence from studies on the association between inflammatory markers and breast cancer mortality. Higher concentrations of most inflammatory markers including CRP, IL-6, and TNF $\alpha$ have been associated with higher risk of breast cancer mortality (Benoy et al, 2004; Heike and Rainer, 2007; Goldberg and Schwertfeger, 2010).

The attenuated association between higher DII scores and breast cancer death when we additionally adjusted for BMI and physical activity may partially be because of confounding by these two energy-balance covariates. Obesity or weight gain has been associated with the quality of dietary intake (Fung et al, 2015) and with breast cancer prognosis (Chan et al, 2014; Widschwendter et al, 2015). However, it is also possible that obesity, a state of low-grade chronic inflammation (Trayhurn and Wood, 2004; Lee et al, 2013), may partly mediate this association. Evidence for mediation is strengthened by findings from welldesigned meta-analyses that combine data from prospective studies of dietary determinants of long-term weight gain, and randomised clinical trials evaluating short-term effects of specific dietary factors on weight changes (Malik et al, 2006; Hu, 2013; Pan et al, 2013). Therefore, the risk of breast cancer death from consuming highly pro-inflammatory diets is likely higher than the $33 \%$ (comparing extreme DII quintiles) we obtained after additional adjustment for BMI and physical activity. Future studies are needed to examine the inflammatory potential of post-diagnosis diet given the suggestion from the current study that dietary inflammatory potential before diagnosis is related to breast cancer death.

The study strengths include the use of the DII specifically designed to assess the inflammatory potential of diet; a large, wellcharacterised study population; a long follow-up period; and central adjudication of breast cancer outcomes. We conducted several sensitivity analyses, including the investigation of the possibility that early malignant lesions might have affected the dietary intake or the report thereof by excluding participants who were diagnosed with invasive breast cancer or who died from it within 3 years from baseline (McBride et al, 2000; Patterson et al, 2012), and our findings were unchanged (Table 4).

Study limitations include known measurement error in using an FFQ for diet assessment (Hebert et al, 2002; Hébert et al, 2014) and the use of a single FFQ at one time point (baseline) only, though diet could change during follow-up. We adjusted for study arm in the multivariable models and investigated the longitudinal stability 
of DII scores in the WHI-OS and DM control arm participants in a separate study and found DII scores not to change significantly over time (Tabung et al, 2015a, b, and unpublished results). In addition, 13 dietary components of the DII were missing from the WHI FFQ, and all 13 of these missing items are anti-inflammatory. Thus, the DII may have a lower predictive ability in this predominantly White and highly educated study population with a more healthful diet consuming food items not on the WHI FFQ list. It is important to note, though, that in the construct validation of the DII in the WHI, the DII computed based on the 32 components available in the WHI FFQ predicted concentrations of inflammatory markers (Tabung et al, 2015b). The DII score calculated from the 32 available components ranged from -7.1 to +5.8 , which is higher than the range of -5.4 to +5.8 obtained in the first DII construct validation study using data from fifteen 24-h dietary recalls with 44 of the 45 DII components (Shivappa et al, $2013 \mathrm{~b}$ ), indicating that the range of DII may be more dependent on the amount of foods actually consumed rather than on the number of available components. Missing data in all covariates included in the multivariable models could potentially bias our HR estimates; however, the women excluded because of missing data were similar to those retained on all characteristics included in Table 1. In addition, when we excluded major contributors of missing data such as family history of breast cancer and NSAID use, there were no material differences in HR estimates (data not shown). Although we adjusted for a large number of potential confounders, there may still exist potential residual or unmeasured confounding. In addition, given the number of tests in Table 3, we cannot rule out that our findings for HER2 + subtype or regional/distant disease are because of chance, though all tests were pre-determined.

Data on treatment were not available, although we did not expect treatment to have an impact on these analyses related to baseline diet estimated well before a breast cancer diagnosis. In the death analyses, we adjusted for race/ethnicity, physical activity, and education, among other potential confounders, but did not adjust for stage (and other tumour characteristics) because stage is more likely a mediator or modifier than a confounder of the association between baseline pre-diagnosis diet and breast cancer death. However, stage may confound the association between postdiagnosis diet and survival from breast cancer, as patients may be advised or choose to eat differently based on tumour characteristics or treatment options (that are often based on tumour characteristics). Post-diagnosis diet was not available for all WHI subjects diagnosed with cancer and, therefore, was not examined in the current analyses.

\section{CONCLUSION}

In this large prospective study of postmenopausal women, a diet characterised by high inflammatory potential, as indicated by higher DII scores, was associated with higher risk of breast cancer death but not incidence of overall breast cancer. Our findings suggest that lowering the inflammatory potential of a woman's diet may be a potential means for reducing the risk of breast cancer death. Future studies should explore whether dietary intervention focused on inflammation could affect the risk of dying from breast cancer.

\section{ACKNOWLEDGEMENTS}

This project was supported by the Prevent Cancer Foundation Living in Pink grant. Dr Tabung was supported by the University of South Carolina's (USC) Office of the Vice President for Research under the SPARC grant, and by an award from the National
Cancer Institute (NCI) of the National Institutes of Health (NIH) F31CA177255. Dr Hébert was supported by an NCI Award K05 CA136975. The National Institutes of Health and the US. Department of Health and Human Services funded the WHI program through Contracts HHSN268201100046C, HHSN268 201100001C, HHSN268201100002C, HHSN268201100003C, HHSN268201100004C, and HHSN271201100004C.

\section{CONFLICT OF INTEREST}

Dr James R Hébert owns controlling interest in Connecting Health Innovations LLC (CHI), a company planning to license the right to his invention of the dietary inflammatory index (DII) from the University of South Carolina in order to develop computer and smart phone applications for patient counselling and dietary intervention in clinical settings. Dr Nitin Shivappa is an employee of $\mathrm{CHI}$.

\section{REFERENCES}

Adebamowo C, Hu FB, Cho E, Spiegelman D, Holmes MD, Willett WC (2005) Dietary patterns and the risk of breast cancer. Ann Epidemiol 15(10): 789-795.

Barbaresko J, Koch M, Schulze MB, Nöthlings U (2013) Dietary pattern analysis and biomarkers of low-grade inflammation: a systematic literature review. Nutr Rev 71(8): 511-527.

Benoy I, Salgado R, Van Dam P, Geboers K, Van Marck E, Scharpé S, Vermeulen PB, Dirix LY (2004) Increased serum interleukin-8 in patients with early and metastatic breast cancer correlates with early dissemination and survival. Clin Cancer Res 10(21): 7157-7162.

Brown P, Subbaramaiah K, Salmon AP, Baker R, Newman RA, Yang P, Zhou XK, Bissonnette RP, Dannenberg AJ, Howe LR (2008) Combination chemoprevention of HER2/neu-induced breast cancer using a cyclooxygenase-2 inhibitor and a retinoid $\mathrm{X}$ receptor-selective retinoid. Cancer Prev Res 1(3): 208-214.

Calhoun B, Collins LC (2015) Predictive markers in breast cancer: an update on ER and HER2 testing and reporting. Semin Diagn Pathol 32(5): 362-369.

Chan D, Vieira AR, Aune D, Bandera EV, Greenwood DC, McTiernan A, Navarro Rosenblatt D, Thune I, Vieira R, Norat T (2014) Body mass index and survival in women with breast cancer: systematic literature review and meta-analysis of 82 follow-up studies. Ann Oncol 25(10): 1901-1914.

Chlebowski R, Blackburn GL, Thomson CA, Nixon DW, Shapiro A, Hoy MK, Goodman MT, Giuliano AE, Karanja N, McAndrew P, Hudis C, Butler J, Merkel D, Kristal A, Caan B, Michaelson R, Vinciguerra V, Del Prete S, Winkler M, Hall R, Simon M, Winters BL, Elashoff RM (2006) Dietary fat reduction and breast cancer outcome: interim efficacy results from the Women's Intervention Nutrition Study. J Natl Cancer Inst 98(24): 1767-1776.

Coghill A, Phipps AI, Bavry AA, Wactawski-Wende J, Lane DS, LaCroix A, Newcomb PA (2012) The association between NSAID use and colorectal cancer mortality: results from the Women's Health Initiative. Cancer Epidemiol Biomarkers Prev 21(11): 1966-1973.

Curb J, McTiernan A, Heckbert SR, Kooperberg C, Stanford J, Nevitt M, Johnson KC, Proulx-Burns L, Pastore L, Criqui M, Daugherty S. WHI Morbidity and Mortality Committee (2003) Outcomes ascertainment and adjudication methods in the Women's Health Initiative. Ann Epidemiol 13(9): S122-S128.

Department of Health and Human Services (2008) 2008 Physical Activity Guidelines for Americans. DHHS: Washington, DC.

DeSantis C, Ma J, Bryan L, Jemal A (2014) Breast cancer statistics, 2013. CA Cancer J Clin 64(1): 52-62.

Esposito K, Marfella R, Ciotola M, Di Palo C, Giugliano F, Giugliano G, D’Armiento M, D’Andrea F, Giugliano D (2004) Effect of a mediterranean-style diet on endothelial dysfunction and markers of vascular inflammation in the metabolic syndrome: a randomized trial. JAMA 292(12): 1440-1446. 
Fung T, Hu FB, Holmes MD, Rosner BA, Hunter DJ, Colditz GA, Willett WC (2005) Dietary patterns and the risk of postmenopausal breast cancer. Int J Cancer 116(1): 116-121.

Fung T, Hu FB, McCullough ML, Newby PK, Willett WC, Holmes MD (2006) Diet quality is associated with the risk of estrogen receptor-negative breast cancer in postmenopausal women. J Nutr 136(2): 466-472.

Fung TT, Pan A, Hou T, Chiuve SE, Tobias DK, Mozaffarian D, Willett WC, Hu FB (2015) Long-term change in diet quality is associated with body weight change in men and women. J Nutr 145(8): 1850-1856.

Ge I, Rudolph A, Shivappa N, Flesch-Janys D, Hébert JR, Chang-Claude J (2015) Dietary inflammation potential and postmenopausal breast cancer risk in a German case-control study. Breast 24(4): 491-496.

George SM, Ballard-Barbash R, Shikany JM, Caan BJ, Freudenheim JL, Kroenke CH, Vitolins MZ, Beresford SA, Neuhouser ML (2014) Better postdiagnosis diet quality is associated with reduced risk of death among postmenopausal women with invasive breast cancer in the Women's Health Initiative. Cancer Epidemiol Biomarkers Prev 23(4): 575-583.

Goldberg J, Schwertfeger KL (2010) Proinflammatory cytokines in breast cancer: mechanisms of action and potential targets for therapeutics. Curr Drug Targets 11(9): 1133-1146.

Harris H, Tworoger SS, Hankinson SE, Rosner BA, Michels KB (2011) Plasma leptin levels and risk of breast cancer in premenopausal women. Cancer Prev Res 4(9): 1449-1456.

Harris R, Chlebowski RT, Jackson RD, Frid DJ, Ascenseo JL, Anderson G, Loar A, Rodabough RJ, White E, McTiernan A. Women's Health Initiative (2003) breast cancer and nonsteroidal anti-inflammatory drugs: prospective results from the Women's Health Initiative. Cancer Res 63(18): 6096-6101.

Hebert JR, Ebbeling CB, Matthews CE, Hurley TG, MA Y, Druker S, Clemow L (2002) Systematic errors in middle-aged women's estimates of energy intake: comparing three self-report measures to total energy expenditure from doubly labeled water. Ann Epidemiol 12(8): $577-586$.

Hébert JR, Hurley TG, Steck SE, Miller DR, Tabung FK, Peterson KE, Kushi LH, Frongillo EA (2014) Considering the value of dietary assessment data in informing nutrition-related health policy. Adv Nutr 5(4): 447-455.

Heike K, Rainer P (2007) Significance of interleukin-6 (IL-6) in breast cancer (review). Breast Cancer Res Treat 102(2): 129-135.

Hong T, Liu A, Cai D, Zhang Y, Hua D, Hang X, Wu X (2013) Preoperative serum C-reactive protein levels and early breast cancer by BMI and menopausal status. Cancer Invest 31(4): 279-285.

Howe LR, Subbaramaiah K, Patel J, Masferrer JL, Deora A, Hudis C, Thaler HT, Muller WJ, Du B, Brown AM, Dannenberg AJ (2002) Celecoxib, a selective cyclooxygenase 2 inhibitor, protects against human epidermal growth factor receptor 2 (HER-2)/neu-induced breast cancer. Cancer Res 62(19): 5405-5407.

Hu FB (2013) Resolved: there is sufficient scientific evidence that decreasing sugar-sweetened beverage consumption will reduce the prevalence of obesity and obesity-related diseases. Obes Rev 14(8): 606-619.

Izano M, Fung TT, Chiuve SS, Hu FB, Holmes MD (2013) Are diet quality scores after breast cancer diagnosis associated with improved breast cancer survival? Nutr Cancer 65(6): 820-826.

Lee H, Lee IS, Choue R (2013) Obesity, inflammation and diet. Pediatr Gastroenterol Hepatol Nutr 16(3): 143-152.

Ma Y, Hébert JR, Li W, Bertone-Johnson ER, Olendzki B, Pagoto SL, Tinker L, Rosal MC, Ockene IS, Ockene JK, Griffith JA, Liu S (2008) Association between dietary fiber and markers of systemic inflammation in the Women's Health Initiative Observational Study. Nutrition 24(10): 941-949.

Mai V, Kant AK, Flood A, Lacey Jr JV, Schairer C, Schatzkin A (2005) Diet quality and subsequent cancer incidence and mortality in a prospective cohort of women. Int J Epidemiol 34(1): 54-60.

Malik V, Schulze MB, Hu FB (2006) Intake of sugar-sweetened beverages and weight gain: a systematic review. Am J Clin Nutr 84(2): 274-288.

McBride C, Clipp E, Peterson BL, Lipkus IM, Demark-Wahnefried W (2000) Psychological impact of diagnosis and risk reduction among cancer survivors. Psychooncology 9(5): 418-427.

Nutrition Coordinating Center at the University of Minnesota M, MN (2013) Nutrition Data System for Research (NDSR). University of Minnesota: Minneapolis, MN.
Pan A, Malik VS, Hao T, Willett WC, Mozaffarian D, Hu FB (2013) Changes in water and beverage intake and long-term weight changes: results from three prospective cohort studies. Int J Obes 37(10): 1378-1385.

Parise C, Caggiano V (2014) Breast cancer survival defined by the ER/PR/ HER2 subtypes and a surrogate classification according to tumor grade and immunohistochemical biomarkers. J Cancer Epidemiol 2014: 11.

Patterson R, Kristal A, Rodabough R, Caan B, Lillington L, Mossavar-Rahmani Y, Simon MS, Snetselaar L, Van Horn L (2003) Changes in food sources of dietary fat in response to an intensive low-fat dietary intervention: early results from the Women's Health Initiative. J Am Diet Assoc 103(4): 454-460.

Patterson R, Kristal AR, Tinker LF, Carter RA, Bolton MP, Agurs-Collins T (1999) Measurement characteristics of the Women's Health Initiative food frequency questionnaire. Ann Epidemiol 9(3): 178-187.

Patterson RE, Rock CL, Kerr J, Natarajan L, Marshall SJ, Pakiz B, Cadmus-Bertram LA (2012) Metabolism and breast cancer risk: frontiers in research and practice. J Acad Nutr Diet 113(2): 288-296.

Prentice RL, Caan B, Chlebowski RT, Patterson R, Kuller LH, Ockene JK, Margolis KL, Limacher MC, Manson JE, Parker LM, Paskett E, Phillips L, Robbins J, Rossouw JE, Sarto GE, Shikany JM, Stefanick ML, Thomson CA, Van Horn L, Vitolins MZ, Wactawski-Wende J, Wallace RB, Wassertheil-Smoller S, Whitlock E, Yano K, Adams-Campbell L, Anderson GL, Assaf AR, Beresford SA, Black HR, Brunner RL, Brzyski RG, Ford L, Gass M, Hays J, Heber D, Heiss G, Hendrix SL, Hsia J, Hubbell FA, Jackson RD, Johnson KC, Kotchen JM, LaCroix AZ, Lane DS, Langer RD, Lasser NL, Henderson MM (2006) Low-fat dietary pattern and risk of invasive breast cancer. J Am Med Assoc 295(6): 629-642.

Sant M, Allemani C, Sieri S, Krogh V, Menard S, Tagliabue E, Nardini E, Micheli A, Crosignani P, Muti P, Berrino F (2007) Salad vegetables dietary pattern protects against HER-2-positive breast cancer: a prospective Italian study. Int J Cancer 121(4): 911-914.

Shivappa N, Hébert JR, Rietzschel ER, De Buyzere ML, Langlois M, Debruyne E, Marcos A, Huybrechts I (2015a) Associations between dietary inflammatory index and inflammatory markers in the Asklepios Study. Br J Nutr 113(4): 665-671.

Shivappa N, Prizment AE, Blair CK, Jacobs Jr DR, Steck SE, Hebert JR (2014) Dietary inflammatory index and risk of colorectal cancer in the Iowa Women's Health Study. Cancer Epidemiol Biomarkers Prev 23(11): 2383-2392.

Shivappa N, Sandin S, Löf M, Hébert JR, Adami HO, Weiderpass E (2015b) Prospective study of dietary inflammatory index and risk of breast cancer in Swedish women. Br J Cancer 113(7): 1099-1103.

Shivappa N, Steck SE, Hurley TG, Hussey JR, Hebert JR (2013a) Designing and developing a literature-derived, population-based dietary inflammatory index. Public Health Nutr 17(8): 1689-1696.

Shivappa N, Steck SE, Hurley TG, Hussey JR, Ma Y, Ockene IS, Tabung FK, Hebert JR (2013b) A population-based dietary inflammatory index predicts levels of C-reactive protein in the Seasonal Variation of Blood Cholesterol Study (SEASONS). Public Health Nutr 17(8): 1825-1833.

Siegel R, Miller KD, Jemal A (2015) Cancer statistics, 2015. CA Cancer J Clin 65(1): 5-29.

Smith-Warner S, Spiegelman D, Yaun SS, Adami HO, Beeson WL, van den Brandt PA, Folsom AR, Fraser GE, Freudenheim JL, Goldbohm RA, Graham S, Miller AB, Potter JD, Rohan TE, Speizer FE, Toniolo P, Willett WC, Wolk A, Zeleniuch-Jacquotte A, Hunter DJ (2001) Intake of fruits and vegetables and risk of breast cancer: a pooled analysis of cohort studies. J Am Med Assoc 285(6): 769-776.

Steck SE, Guinter M, Zheng J, Thomson CA (2015) Index-based dietary patterns and colorectal cancer risk: a systematic review. Adv Nutr 6(6): 763-773.

Tabung FK, Steck SE, Ma Y, Liese AD, Zhang J, Caan B, Hou L, Johnson KC, Mossavar-Rahmani Y, Shivappa N, Wactawski-Wende J, Ockene JK, Hebert JR (2015a) The association between dietary inflammatory index and risk of colorectal cancer among postmenopausal women: results from the Women's Health Initiative. Cancer Causes Control 26(3): 399-408.

Tabung FK, Steck SE, Zhang J, Ma Y, Liese AD, Agalliu I, Hou L, Hurley TG, Hingle M, Jiao L, Martin LW, Millen EA, Park HL, Rosal CM, Shikany JM, Shivappa N, Ockene JK, Hebert JR (2015b) Construct validation of the dietary inflammatory index among postmenopausal women. Ann Epidemiol 25(6): 398-405. 
Terry P, Suzuki R, Hu FB, Wolk A (2001) A prospective study of major dietary patterns and the risk of breast cancer. Cancer Epidemiol Biomarkers Prev 10(12): 1281-1285.

Trayhurn P, Wood IS (2004) Adipokines: inflammation and the pleiotropic role of white adipose tissue. Br J Nutr 92(03): 347-355.

Widschwendter P, Friedl TW, Schwentner L, DeGregorio N, Jaeger B, Schramm A, Bekes I, Deniz M, Lato K, Weissenbacher T, Kost B, Andergassen U, Jueckstock J, Neugebauer J, Trapp E, Fasching PA, Beckmann MW, Schneeweiss A, Schrader I, Rack B, Janni W, Scholz C (2015) The influence of obesity on survival in early, high-risk breast cancer: results from the randomized SUCCESS A trial. Breast Cancer Res 17(1): 129.

Wirth MD, Shivappa N, Steck SE, Hurley TG, Hebert JR (2015) The dietary inflammatory index is associated with colorectal cancer in the National Institutes of Health-American Association of Retired Persons Diet and Health Study. Br J Nutr 113(11): 1819-1827.
Wirth MD, Hébert JR, Shivappa N, Hand GA, Hurley TG, Drenowatz C, McMahon D, Shook RP, Blair SN (2016) Anti-inflammatory Dietary Inflammatory Index scores are associated with healthier scores on other dietary indices. Nutr Res 36(3): 214-219.

Women's Health Initiative Study Group (1998) Design of the Women's Health Initiative clinical trial and observational study. Control Clin Trials 19(1): 61-109.

Zamora-Ros R, Shivappa N, Steck SE, Canzian F, Landi S, Alonso MH, Hébert JR, Moreno V (2014) Dietary inflammatory index and inflammatory gene interactions in relation to colorectal cancer risk in the Bellvitge colorectal cancer case-control study. Genes Nutr 10(1): 1-9.

This work is published under the standard license to publish agreement. After 12 months the work will become freely available and the license terms will switch to a Creative Commons AttributionNonCommercial-Share Alike 4.0 Unported License.

Supplementary Information accompanies this paper on British Journal of Cancer website (http://www.nature.com/bjc) 